\title{
The genome of the Gram-positive metal- and sulfate-reducing bacterium Desulfotomaculum reducens strain $\mathrm{Ml}-1$
}

Pilar Junier, ${ }^{1 \dagger}$ Thomas Junier, ${ }^{2}$ Sheila Podell, ${ }^{3}$

David R. Sims, ${ }^{4}$ John C. Detter, ${ }^{4}$

Athanasios Lykidis, ${ }^{5}$ Cliff S. Han, ${ }^{4}$

Nicholas S. Wigginton, ${ }^{1 \neq}$ Terry Gaasterland ${ }^{3}$ and

Rizlan Bernier-Latmani ${ }^{1 *}$

${ }^{1}$ Environmental Microbiology Laboratory, Ecole

Polytechnique Fédérale de Lausanne, Lausanne 1015,

Switzerland.

${ }^{2}$ Computational Evolutionary Genomics Group,

University of Geneva, Geneva 1211, Switzerland.

${ }^{3}$ Marine Biological Research Division, Scripps Institution

of Oceanography, La Jolla, CA 92037, USA.

${ }^{4}$ DOE Joint Genome Institute, Bioscience Division, Los

Alamos National Laboratory, Los Alamos, NM 87545 ,

USA.

${ }^{5}$ DOE-Joint Genome Institute, Genome Biology

Program, Walnut Creek, CA 94598, USA.

\section{Summary}

Spore-forming, Gram-positive sulfate-reducing bacteria (SRB) represent a group of SRB that dominates the deep subsurface as well as niches in which resistance to oxygen and dessication is an advantage. Desulfotomaculum reducens strain $\mathrm{Ml}-1$ is one of the few cultured representatives of that group with a complete genome sequence available. The metabolic versatility of this organism is reflected in the presence of genes encoding for the oxidation of various electron donors, including three- and fourcarbon fatty acids and alcohols. Synteny in genes involved in sulfate reduction across all four sequenced Gram-positive SRB suggests a distinct sulfate-reduction mechanism for this group of bacteria. Based on the genomic information obtained for sulfate reduction in $D$. reducens, the transfer of electrons to the sulfite and APS reductases is proposed to take place via the quinone pool and heterodisulfide reductases respectively. In addition,

Received 24 April, 2009; accepted 22 March, 2010. *For correspondence. E-mail rizlan.bernier-latmani @epfl.ch; Tel. (+41) 21693 5001; Fax (+41) 21693 6205. Present addresses: 'Laboratory of Microbiology, University of Neuchâtel, Neuchâtel 2000, Switzerland; ‡Science, 1200 New York Avenue NW, Washington DC, USA. both $\mathrm{H}_{2}$-evolving and $\mathrm{H}_{2}$-consuming cytoplasmic hydrogenases were identified in the genome, pointing to potential cytoplasmic $\mathrm{H}_{2}$ cycling in the bacterium. The mechanism of metal reduction remains unknown.

\section{Introduction}

The genus Desulfotomaculum contains sulfate-reducing bacteria (SRB) that form heat-, oxygen- and desiccationresistant endospores (Widdel and Bak, 1992). Because of their ability to form spores, members of this genus thrive in habitats where anoxic conditions are not maintained permanently and where desiccation occasionally occurs. As a result, Desulfotomaculum and the closely related genus Desulfosporosinus tend to be the dominant SRB in subsurface environments disturbed by human activities, such as mines, as well as sites where the groundwater level is subject to significant seasonal fluctuations. Phylogenetic studies of the bacterial communities in deep mines in Japan (Ishii et al., 2000) and South Africa (Moser et al., 2003) illustrate the importance of Desulfotomaculum spp. in those environments. A separate investigation $4 \mathrm{~km}$ deep in a South African mine revealed that species of Desulfotomaculum and Methanobacterium dominate the microbial communities in those environments (Moser et al., 2005). Recently, the relevance of Desulfotomaculum and other Gram-positive spore-forming bacteria, particularly Desulfosporosinus and Clostridium has come to the fore for the bioremediation of $\mathrm{U}(\mathrm{VI})$-contaminated sites and it appears as though these organisms could play an important role at these sites following electron donor amendments (Chang et al., 2001; Madden et al., 2007; N'Guessan et al., 2008).

Desulfotomaculum reducens $\mathrm{Ml}-1$ was isolated from marine sediments heavily contaminated with chromium from Mare Island Naval Shipyard (Tebo and Obraztsova, 1998). It can use a wide range of organic compounds as electron donors, including short-chain fatty acids such as propionate, butyrate and valerate, alcohols such as methanol, ethanol, n-propanol and n-butanol as well as lactate, pyruvate and glucose. More importantly, it can use a large number of electron acceptors for growth: sulfate, 
thiosulfate, dithionite, as well as elemental sulfur. It is one of the few SRB able to grow by coupling the oxidation of organic compounds to the reduction of $\mathrm{Fe}(\mathrm{III})$ to $\mathrm{Fe}(\mathrm{II})$ (Tebo and Obraztsova, 1998).

As is typical of many SRB, D. reducens ferments pyruvate. However, a recent characterization of $D$. reducens has unveiled unusual metabolic properties. The most striking result is that spores of $D$. reducens are able to catalyse the reduction of $\mathrm{U}(\mathrm{VI})$ when $\mathrm{H}_{2}$, a product of pyruvate fermentation, is provided as an electron donor and when cell-free medium collected after cell growth (spent medium) is added (Junier et al., 2009). Under these conditions, the presence of competing electron acceptors such as nitrate or sulfate does not affect $\mathrm{U}(\mathrm{VI})$ reduction (Junier et al., 2010). This is significant due to the extensive nitrate contamination found concomitantly with $\mathrm{U}(\mathrm{VI})$ in various US Department of Energy (DOE) sites and the prevalence of nitrate outcompeting $\mathrm{U}(\mathrm{VI})$ as an electron acceptor for many microorganisms (Elias et al., 2003; Luo et al., 2005).

Desulfotomaculum reducens $\mathrm{Ml}-1$ is an excellent example of a microorganism to be investigated in more detail because its unusual metabolic characteristics make it effectively both a sulfate- and a metal-reducing bacterium. In addition, it is one of the few Gram-positive SRB for which a complete genome sequence is available. The other two are Desulfotomaculum acetoxidans (a close relative to $D$. reducens) and Candidatus Desulforudis audaxviator that was sequenced from DNA obtained from South African mine (Chivian et al., 2008). It is one of only three SRB with a genome sequence available and able to couple growth to $\mathrm{Fe}(\mathrm{III})$ reduction. The other two are Desulfotalea psychrophila (Knoblauch et al., 1999) and Desulfobulbus propionicus (Holmes et al., 2004).

Eighteen draft and finished SRB genome sequences are available to date and were used for comparison: seven Desulfovibrio spp. (Dv. desulfuricans G20, Dv. desulfuricans ATCC 27774, Dv. piger, Dv. salexigens, Dv. vulgaris Miyazaki, Dv. vulgaris DP4, Dv. vulgaris Hildenborough), Desulfonatronospira thiodismutans, Desulfohalobium retbaense, Desulfococcus oleovorans, Desulfobacterium autotrophicum, Desulfobulbus propionicus, Desulfomicrobium baculatum, Desulfotalea psychrophila, Candidatus Desulforudis audaxviator, Desulfonispora thiosulfatigenes and two Desulfotomaculum spp. (D. reducens and $D$. acetoxidans). The latter four are Gram-positive.

In this article, we present the complete genome sequence of $D$. reducens strain $\mathrm{Ml}-1$. Using manual annotation, metabolic information as well as the comparison to genomes of the eighteen above-mentioned SRB, we describe general features of the $D$. reducens genome including genetic components involved in central metabolic pathways, sulfate reduction, hydrogen metabolism and metal reduction.

\section{Results and discussion}

\section{General genome features}

The finished genome of $D$. reducens consists of a single circular chromosome, 3608104 base pairs (bp) long, with a $\mathrm{G}+\mathrm{C}$ content of $43 \%$ (Table 1 and Fig. 1). 71 tRNAs were identified. In addition to the 69 standard tRNAs, two are for nonstandard aminoacids: pseudouridine (dred_R0046) and selenocysteine (dred_R0069). The genome contains eight almost identical copies of the three rRNAs (5S, 16S and 23S) but in addition, we found $16 \mathrm{~S}$ and 5S rRNA genes that were slightly longer than the ones pertaining to operons (1629 bp instead of $1612 \mathrm{bp}$ for $16 \mathrm{~S}$ rRNA and $205 \mathrm{bp}$ instead of $117 \mathrm{bp}$ for $5 \mathrm{~S}$ rRNA). A combination of automated annotation and extensive manual curation predicted 3324 protein-coding sequences (CDS), of which, 2334 (70\%) were assigned functions.

\section{Central and electron donor metabolism}

Central metabolic pathways such as the EmbdenMeyerhoff-Parnas (glycolysis) pathway and the reductive pentose phosphate pathway are present. The glycolysis pathway (Fig. S1) and the reductive pentose phosphate pathway (Fig. S2) are complete. A partial reductive citric acid cycle is also present that allows the transformation of oxaloacetate to succinate via malate and fumarate and succinyl-coA to isocitrate via $\alpha$-ketoglutarate. However, it is unclear whether the succinate to succinyl-coA step is possible because the succinyl-coA synthetase normally

Table 1. Desulfotomaculum reducens strain Ml-1 genome statistics.

\begin{tabular}{lc}
\hline Characteristic & Value \\
\hline Chromosome size (bp) & 3608104 \\
G+C ratio (\%) & 43.28 \\
Coding density (\%) & 85.5 \\
No. of predicted protein coding gene & 324 \\
No. of predicted proteins unique to & $515(15.5)$ \\
$D$. reducens (\%) & 8 \\
Number of rRNA operons & 71 \\
Number of tRNA genes & $2334(70.2)$ \\
No. of predicted proteins with putative & \\
function (\%) & $990(29.8)$ \\
No. of predicted proteins with unknown & \\
$\quad$ function (\%) & 510 \\
Genes coding transmembrane proteins & \\
BLASTP comparison against completed & \\
$\quad$ microbial genome database (No. of top hits) & 2553 \\
Firmicutes & 2375 \\
Clostridia & 178 \\
Bacilli & 50 \\
Deltaproteobacteria & 32 \\
Syntrophomonadaceae & \\
\hline
\end{tabular}

$\%$ GC statistics are for protein coding sequences only. Criteria for BLASTP match inclusion: (i) BLASTP e-value $1 e-5$ or lower; (ii) alignment covering $>70 \%$ of both query and subject. 




Fig. 1. Circular representation of the genome of Desulfotomaculum reducens strain $\mathrm{Ml}-1$. From the outside inwards: Genes on forward strand (blue) and genes on reverse strand (black) and tRNA genes (green), genes with best blast hit from $D$. acetoxidans (red), genes with best blast hit from Desulfitobacterium hafniense Y51 (blue), hypothetical proteins (brown), transposases and integrases (green), and $\mathrm{G}+\mathrm{C}$ content (purple).

active in this pathway (E.C. 6.2.1.5) is absent from the $D$. reducens genome (Fig. S3). Without this enzyme, the partial citric acid pathway does not allow the formation of $\alpha$-ketoglutarate from oxaloacetate, suggesting that glutamate metabolism is lacking in $D$. reducens. In fact, the organism does not grow in the absence of yeast extract, suggesting that it is a fastidious bacterium (Fig. S4).

A characteristic of $D$. reducens is its ability to utilize a large number of electron donors: lactate, pyruvate, glucose, short-chain fatty acids such as propionate, butyrate and valerate, and alcohols such as methanol, ethanol, n-propanol or n-butanol (Tebo and Obraztsova, 1998). Fig. 2 shows the pathways involved in the oxidation of butyrate (green) and ethanol (purple).

Pyruvate is an intermediate in the oxidation of several electron donors (propionate, lactate, glucose) in addition to being itself an electron donor and fermentative substrate. The pathways for the metabolism of propionate, lactate and glucose via pyruvate are shown in yellow in Fig. 2. An interesting feature of the $D$. reducens genome is that it encodes genes for all three potential pyruvate transformation mechanisms (Fig. S5; Fig. 2) (White, 2000). Decarboxylation by the pyruvate dehydrogenase (PDH) (dred_1893) yields acetate, $\mathrm{CO}_{2}$ and $\mathrm{NADH}$; decarboxylation by the pyruvate-ferredoxin oxidoreductase (PFOR) (dred_0047-50) yields acetate, $\mathrm{CO}_{2}$ and $\mathrm{H}_{2}$ and decarboxylation by the pyruvate-formate lyase (PFL) (dred_2750-53) yields acetate and formate. Experimental evidence for activity of the former two is available (Junier et al., 2009; Junier et al., 2010). In order to produce $\mathrm{H}_{2}$ from the fermentation of pyruvate, an $\mathrm{H}_{2}$-evolving hydrogenase is involved (see hydrogen metabolism section).

Acetate is the product of the oxidation of all electron donors because $D$. reducens is an incomplete oxidizer. Thus, acetyl-CoA is also an intermediate in many pathways. Surprisingly, we were unable to identify a phosphotransacetylase to catalyse the formation of acetylphosphate from acetyl-CoA in the genome of $D$. reducens (Fig. S5) despite comparing the phosphotransacetylase from $D$. acetoxidans to the entire $D$. reducens genome using BLASTP. Nonetheless, an acetate kinase (E.C. 2.7.2.1; dred_2094) was identified and is predicted to catalyse the transformation of acetyl-phosphate to acetate with the production of ATP. We also identified an acetyl-CoA ligase (E.C. 6.2.1.13; dred_2081) that produces acetate and ATP from acetyl-CoA directly and that is likely to be involved in energy production from the acetyl-CoA intermediate (Fig. S5). 




Fig. 2. Metabolic reconstruction of $D$. reducens based on known growth substrates and metabolic capacities. Arrows indicate metabolic flows: dashed lines represent putative electron flow. The sole protein shown in dark blue contains selenocysteine. Abbreviations are: $\mathrm{DH}$, dehydrogenase; $\mathrm{H}_{2}$ ase, hydrogenase; DsrMK, menaquinol oxidizing complex; DsrABC, sulfite reductase; NrfHA, nitrite reductase; Hdr, heterodisulfide reductase; MvhD, methyl viologen reducing hydrogenase, delta subunit; Sat, sulfate adenyl transferase; QmoAB, Hdr- and Mvh-containing protein complex; FeS, iron sulfur protein; Fd, ferredoxin, EtfAB, electron-transfer flavoprotein; OR, oxidoreductase; PPi, pyrophasphate.

Two complete non-identical copies of the aerobic-type carbon monoxide dehydrogenase (CoxMSL) are present (dred_2774-6 and dred_1502-4). This protein is a dimer of heterotrimers: it contains a molybdoprotein, a flavoprotein and an $\mathrm{Fe}-\mathrm{S}$ protein and catalyses the oxidation of $\mathrm{CO}$ coupled to the reduction of an electron acceptor (Schubel et al., 1995). This aerobic-type carbon monoxide dehydrogenase $(\mathrm{CODH})$ was recently identified in the complete genomes of two other anaerobes: Carboxydothermus hydrogenoformans (Luo et al., 2005) and Moorella thermoacetica (moth_1958-60) (Pierce et al., 2008). This suggests that the aerobic-type CODH may function with other electron acceptors than $\mathrm{O}_{2}$ (e.g., sulfate). We tested $D$. reducens for its ability to utilize $\mathrm{CO}$ as an electron donor in the presence of sulfate as an electron acceptor with or without an additional electron donor (lactate). We found that $\mathrm{CO}$ was inhibitory to sulfate reduction in the presence of lactate and did not support sulfate reduction in the presence of $\mathrm{CO}$ alone (Fig. S6) suggesting no direct involvement of $\mathrm{CODH}$ in bulk $\mathrm{CO}$ oxidation. Two studies (Voordouw, 2002; Pereira et al., 2008) suggest that CO may be produced during sulfate reduction in Desulfovibrio vulgaris. The transcriptomic study (Pereira et al., 2008) suggests that $\mathrm{CO}$ may be produced during pyruvate decarboxylation and is consistent with $\mathrm{CO}$ serving as a physiological electron donor for energy-producing processes at low concentrations. Thus, even if the aerobic type $\mathrm{CODH}$ does not support growth with $\mathrm{CO}$ as an electron donor and $\mathrm{CO}$ is toxic to cells at the concentrations considered, $\mathrm{CODH}$ may be involved in the cycling of low levels of $\mathrm{CO}$ within the cell during sulfate reduction (see sulfate section).

\section{Sulfate catabolism}

Unlike other types of respiration where the terminal reductases are located on the cytoplasmic (or the outer) 
membrane, sulfate reduction is biochemically challenging because of the cytoplasmic localization of the terminal reductases [adenosine phosphosulfate (APS) reductase and sulfite reductase]. This means that the direct translocation of protons across the membrane coupled to electron transport cannot take place. A model for the pathway of dissimilatory sulfate reduction involving 'hydrogen cycling' was developed for Desulfovibrio vulgaris (Odom and Peck, 1981). The general scheme is predicated on the production of $\mathrm{H}_{2}$ that diffuses freely into the periplasm and carries with it both electrons and protons. In the $\mathrm{H}_{2}$ cycling model, hydrogen gas in the periplasm donates electrons to periplasmic hydrogenases that transfer them to periplasmic $c_{3}$ cytochromes, releasing protons into the periplasm and generating a proton motive force. The hydrogen cycling model has been expanded to include formate and $\mathrm{CO}$ as potential intermediates shuttling electrons from the cytoplasm to the periplasm and is termed 'redox cycling' (Pereira et al., 2008). Similarly to hydrogen cycling, periplasmic formate dehydrogenases oxidize formate and release protons, electrons and $\mathrm{CO}_{2}$ into the periplasm (Pereira et al., 2008). Cytoplasmic $\mathrm{CO}$ is converted to periplasmic $\mathrm{CO}_{2}$ and $\mathrm{H}_{2}$ via a membrane-spanning CODHhydrogenase complex (Voordouw, 2002). Subsequently, the electrons that have been accumulated in the periplasmic $c_{3}$ cytochrome pool are transferred back into the cytoplasm to the APS and sulfite reductases through transmembrane complexes (e.g., Qmo, Rnf, Dsr, Hmc) (Heidelberg et al., 2004).

Desulfotomaculum reducens is a Gram-positive SRB and, thus, lacks a periplasmic space as well as periplasmic proteins. As a result, the electron flow during sulfate reduction must differ from that in $D v$. vulgaris. In this section, we propose a mechanism by which $D$. reducens obtains energy from sulfate reduction in the absence of a periplasm (shown in red in Fig. 2).

Activation of sulfate to APS. The sulfate adenyltransferase (dred_0635) releases pyrophosphate during the conversion of sulfate to APS. A fourteen transmembrane helix $(\mathrm{TMH})$ proton-translocating pyrophosphatase (Fig. 2) is encoded in the genome of $D$. reducens (dred_2985) as well as in the genome of all three other Gram-positive SRB. In contrast, only a soluble pyrophosphatase is found in Gram-negative SRB. The transmembrane pyrophosphatase may allow the translocation of protons during the cleavage of the pyrophosphate diphosphate bond, suggesting that the activation of sulfate may contribute to the establishment of a proton motive force. Its presence in all four Gram-positive SRB sequenced to date is consistent with a strategy to obtain energy from sulfate reduction in the absence of periplasmic proteins.
Reduction of APS to sulfite. Adjacent to the sulfate adenyltransferase is the APS reductase (dred_0636-7) that is homologous to APS reductases from other SRB. However, the alpha subunit (dred_0637) of the APS reductase in $D$. reducens was predicted to be membraneanchored and outside-facing using the transmembrane helix (TMH) prediction algorithm TMHMM (http:// www.cbs.dtu.dk/services/TMHMM). Out of the eighteen SRB genomes, $D$. reducens is the only one for which the APS reductase alpha subunit is predicted to be membrane-anchored (with a probability $>85 \%$ ). Note that the Desulfonispora sp. genome sequence does not cover this region and thus, the APS reductase from that organism was not included in this analysis. Bioinformatic evidence of the membrane-anchored localization for the $D$. reducens APS reductase will need to be confirmed by biochemical analyses as single transmembrane helix predictions are not as reliable as multi-helix predictions. However, there is a precedent for this observation. Immunocytochemical evidence shows the association of the APS reductase with the cytoplasmic membrane in the thermophilic SRB Desulfovibrio thermophilus whereas it confirms the cytoplasmic localization of the protein in $D v$. vulgaris and Dv. gigas (Kremer et al., 1988).

Associated with the adenyltransferase and the APS reductase are a heterodisulfide reductase $(\mathrm{Hdr})$ (dred_0638) and the fusion protein of a heterodisulfide reductase and the delta subunit of the methyl-viologenreducing [Ni-Fe] hydrogenase (Mvh) (dred_0639). The latter two ORFs (dred_0638 and dred_0639) are conserved in all SRB sequenced to date (Fig. 3) and represent two of the three genes of the QmoABC complex in $D$ v. vulgaris. QmoABC is a transmembrane complex that, in $D v$. vulgaris, allows the transfer of electron from the periplasmic $c_{3}$ cytochrome pool to the terminal reductases in the cytoplasm (Haveman et al., 2004). While the gamma subunit (QmoC) of QmoABC includes TMHs in all Gram-negative SRB, the three examples of Gram-positive SRB (D. reducens, D. acetoxidans and Candidatus Desulforudis - the Desulfonispora $\mathrm{sp}$. draft sequence does not include the appropriate region) lack TMHs. In $D$. reducens, $\mathrm{QmoC}$ is completely absent. Because the Qmo operon is adjacent to the APS reductase, it has been suggested that it may be involved in transferring electrons from periplasmic $c$-type cytochromes to this cytoplasmic reductase in Dv. desulfuricans (Pires et al., 2003; Haveman et al., 2004). The fact that there is no transmembrane subunit in the Qmo complex in the three Gram-positive SRB for which sequence is available suggests that the Qmo complex is unlikely to catalyse transmembrane electron transfer in those bacteria. Nonetheless, it is possible that $\mathrm{QmoAB}$ in $D$. reducens serves as an electron donor to APS reductase if electrons are donated to the complex from a cytoplasmic source such 
Desulfotomaculum reducens $\mathrm{MI}-1$

Desulfotomaculum acetoxidans, DSM 771

Candidatus Desulforudis audaxviator MP104C

Desulfobulbus propionicus, DSM 2032

Desulfonatrospira thiodismutans AS03-1

Desulfotalea psychrophila LSv54

Candidatus Desulfococcus oleovorans Hxd3

Desulfohalobium retbaense, DSM 5692

Desulfobacterium autotrophicum, HRM2

Desulfomicrobium baculatum X, DSM 4028

Desulfovibrio vulgaris Hildenborough

Desulfovibrio vulgaris Miyazaki F

Desulfovibrio vulgaris DP4

Desulfovibrio desulfuricans G20

Desulfovibrio desulfuricans ATCC 27774

Desulfovibrio salexigens DSM 2638

Desulfovibrio piger ATCC 29098



aprB aprA qmoA $q m o \mathrm{~B}$ qmoC hdrB aprB aprA qmoA qmoB qmoC hdrB

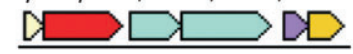
aprB aprA qmoA qmoB qmoC trRNA $\longrightarrow \square$ aprB aprA qmoA qmoB qmoC $\longrightarrow \square$ apri aprA qmoA qmoB qmoC $\longrightarrow$ aprB aprA qmoA qmoB qmoC apri aprA qmoA aprB aprA qmoA qmoB qmoC $\longrightarrow$ apri aprA qmoA $q m o \mathrm{~B} \quad q m o \mathrm{C} c s p \mathrm{~L}$ apri aprA qmoA qmoB qmoC csp apri aprA qmoA qmoB qmoC hyp $\mathrm{D}$ aprB aprA qmoA qmoB qmoC hyp $\mathrm{D} \longrightarrow \square$ aprB aprA qmoA qmoB qmoC hyp aprB aprA qmoA qmoB qmoC hyp (aprA aprB aprA qmoA qmoB qmoC hyp $\mathrm{D} \longrightarrow$ aprB aprA qmoA qmoB qmoC hyp $\longrightarrow$ aprB aprA qmoA qmoB qmoC hyp aprB aprA $\longrightarrow$
Fig. 3. aprBA and $q m o A B C$ organization for all available SRB genome sequences. aprBA, beta and alpha subunit of the APS reductase; qmoABC, alpha, beta and gamma subunits of the quinone-interacting membrane-bound oxidoreductase. QmoC is the transmembrane subunit but is absent in $D$. reducens and soluble in $D$. acetoxidans and $D$. audaxviator. cspL, cold shock protein; hyp, hypothetical protein; hdrB, heterodisulfide reductase; qmoAB, genes encoding a heterodisulfide reductase and a methyl-viologen reducing hydrogenase protein complex. ulfide reductase (Pires et al., 2006). Using the Ortholog Neighborhood Viewer tool in JGI-IMG (http://img.jgi. doe.gov) for $D v$. vulgaris Hildenborough's dsrMKJOP against all SRB genomes, we were able to identify orthologous genes for dsMK but not for dsrJOP in $D$. reducens (Fig. 4). These genes were annotated as the gamma subunit of a nitrate reductase (dred_3199) and a putative reductase (dred_3198). The gamma subunit of the nitrate reductase (dred_3199, dsrM) is a b-type cytochrome and is predicted to have five transmembrane helices and to pertain to a protein family (PF02665) that receives electrons from the quinone pool. While there is some similarity between dred_3198-9 and dsiMK from $D v$. vulgaris Hildenborough, it is clear that there is a dichotomy between these genes and associated proteins in Gram-positive bacteria and their counterparts in Gramnegative bacteria. In fact, a BLAST analysis of the 
Desulfotomaculum reducens MI-1

Desulfotomaculum acetoxidans, DSM 771

Candidatus Desulforudis audaxviator MP104C

Desulfonispora thiosulfatigenes GKNTAUT

Desulfobulbus propionicus, DSM 2032

Desulfonatrospira thiodismutans AS03-1

Desulfotalea psychrophila LSv54

Candidatus Desulfococcus oleovorans $\mathrm{Hxd} 3$

Desulfohalobium retbaense, DSM 5692

Desulfobacterium autotrophicum, HRM2

Desulfomicrobium baculatum X, DSM 4028

Desulfovibrio vulgaris Hildenborough

Desulfovibrio vulgaris Miyazaki F

Desulfovibrio vulgaris DP4

Desulfovibrio desulfuricans G20

Desulfovibrio desulfuricans ATCC 27774

Desulfovibrio salexigens DSM 2638

Desulfovibrio piger ATCC 29098
FeS dsrM dsrk dsrC cbiA

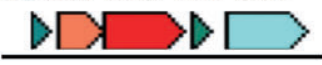

Fes $d s r \mathrm{M} d s r \mathrm{~K} \quad d s r \mathrm{C}$ cbiA

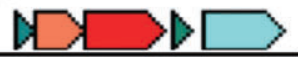

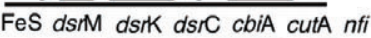

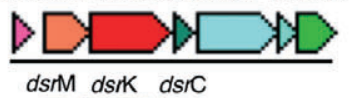
$d s r \mathrm{M} d s r \mathrm{~K}$ dsrC

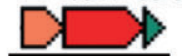

dsrM dsrK DsrJ Dsro DsrP


dsrM dsrK DsrJDsro DsrP


dsrM dsrK DsrJ DsrO DsiP LLL dsrM dsrk DsrJ DsrO DsrP


dsrM dsrK DsrJ DsrO DsrP



dsrM dsrK DsrJ DsrO DsrP

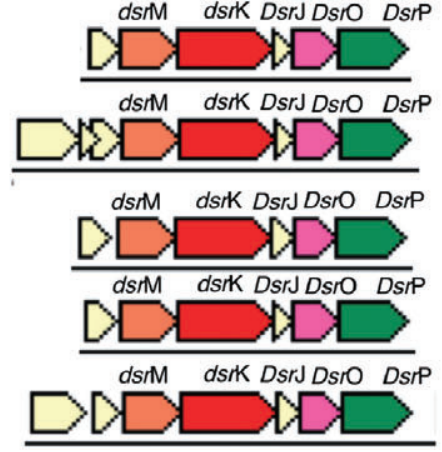

Fig. 4. Gene organization for the dsr operon for all available genome sequences. cbiA, cobyrinic acid synthase; cutA, copper toxicity protein; FeS, iron sulfur protein; nfi, endonuclease V; asp, aspartyl aminopeptidase. Unlabelled genes are hypothetical proteins. membrane-spanning protein encoded by dred_3199 yields no hits for Gram-negative SRB. It has been suggested that the Dsr complex is made up of two modules DsrMK and DsrJOP and that the DsrMK module might be involved in menaquinol oxidation as well as the reduction of a cytoplasmic substrate (Pires et al., 2006). That description of the activity of DsrMK, in the absence of DsrJOP, is consistent with its potential electron transport role (from the quinone pool to a cytoplasmic protein) in $D$. reducens and other Gram-positive SRB (Fig. 2).

Adjacent to ds MK, arranged as part of what appears to be the same operon, the $D$. reducens genome (and that of the other three sequenced Gram-positive SRB) encodes a soluble protein (dred_3197) that corresponds to the gamma subunit of the dissimilatory sulfite reductase (DsrC) (Fig. 4). In D. vulgaris, DsrC has recently been implicated in serving as an electron shuttle between the membrane-bound DsrMKJOP complex and the cytoplasmic DsrAB sulfite reductase (Oliveira et al., 2008). In that study, DsrC was found to interact with DsrK (the cytoplasmic catalytic subunit) and to form a persulfide-containing intermediate that once dissociated from DsrAB was released as sulfide. We hypothesize that, in $D$. reducens and other Gram-positive SRB, DsrC may similarly transfer 




Fig. 5. Seven hdr loci in $D$. reducens. etfAB, electron transfer flavoprotein; paaH, 3-hydroxybutyryl-CoA dehydrogenase; crt, 3-hydroxybutyryl-CoA dehydratase; $b c d$, butyryl-CoA dehydrogenase; atoB, acetyl-CoA C-acetyltransferase; cat2, 4-hydroxybutyrate coenzyme A transferase; bioB, biotin synthetase; bacA, undecaprenyldiphosphatase; $\mathrm{FeS}$, iron-sulfur protein; $m v h \mathrm{D}$, methyl viologen hydrogenase, delta subunit; MFS, major facilitator superfamily protein; OR, oxidoreductase; tmh, transmembrane helices-containing protein; $h d r \mathrm{~A}, h d r \mathrm{~B}, h d r \mathrm{C}, h d r \mathrm{D}, h d r \mathrm{~F}$, different heterodisulfide reductase subunits; $h d r \mathrm{~F} 1$, transmembrane heterodisulfide reductase; hdrA1, NADH-dependent heterodisulfide reductase. Locus I is dred_0137 to dred_0148; Locus II is dred_0633 to dred_0639 (includes $q$ moAB which are dred_0638-9); locus III is dred_0358 to dred_0354; locus IV is dred_1325 to dred 1330; locus V Is dred 1777 to dred_1786; locus VI is dred_0427 to dred_0433 and locus VII is dred_0689 to dred_0690. The asterisk '*' indicates a selenocysteine-containing protein. electrons from DsrK to DsrAB, which in turn, is involved in the reduction of sulfite to sulfide. The overall electron transfer would then take place from the quinone pool to DsrM, DrsK, DsrC and finally DsrAB (Fig. 2).

Electron flow to APS and sulfite reductases. Other transmembrane electron transfer complexes present in $D v$. vulgaris (e.g., HmcABCDEF or RnfABCDGE) are not found in $D$. reducens or other Gram-positive SRB, which is consistent with the presence of a distinct sulfate reduction mechanism in Gram-positive SRB. In D. reducens, the electrons are generated via the oxidation of organic substrates and transit via $\mathrm{NADH}, \mathrm{H}_{2}$, formate, $\mathrm{CO}$ as well as various reduced soluble electron transport proteins such as ferredoxin (dred_2206) and electron transfer flavoproteins (EtfAB) (dred_1778-9, dred_1538-9, dred_0572-3 and dred_0367-8) (Fig. 2).

Formate is oxidized via formate dehydrogenase (dred_1112-19) that includes a ten-TMH transmembrane subunit (dred_1116) annotated as a polysulfide reductase and that is part of a protein family (PF03916) that is known to participate in electron exchange with the quinone pool. The oxidation of formate to $\mathrm{CO}_{2}$ could be coupled to sodium translocation (Fig. 2) as the last ORF in the operon (dred_1119) encodes a sodium-dependent transporter. This ORF is slightly upregulated during lactate- dependent sulfate reduction (data not shown), suggesting the formation of formate as an intermediate of lactate oxidation. The electrons are presumably passed on to the quinone pool. Similarly, NADH is oxidized by a quinoneinteracting, proton-translocating $\mathrm{NADH}$ dehydrogenase (DH) (dred_2036-46) that also passes electron to the quinone pool (Fig. 2). From the quinone pool, the electrons are transferred to DsrM and on to sulfite reductase, as suggested above.

Heterodisulfide reductase. The genome of $D$. reducens encodes numerous heterodisulfide reductases ( $\mathrm{Hdr}$ ) found in seven loci (Fig. 5). A recent analysis of the genome of Desulfobacterium autotrophicum HRM2 showed nine hdr loci in that organism. Many of the cytoplasmic $\mathrm{Hdr}$ in $\mathrm{Db}$. autotrophicum were presumed to be involved in (i) the transfer of electron from transmembrane complexes to the sulfite reductase, (ii) the reduction of the disulfide bond of the DsrABC complex, and (iii) the reduction of ferredoxin (Strittmatter et al., 2009). In $D$. reducens, the $h d r$ loci include several gene configurations: hdrA associated with mvhD (loci I, II and IV), hdrA, $h d r \mathrm{~B}$ and $h d r \mathrm{C}$ in close proximity (loci II, III, IV), a membrane-spanning $h d r \mathrm{~F}$ associated with etfAB and with hdrD (locus V) and hdrD alone (loci VI and VII) (Fig. 5). Locus I consists of two identical repeats of the same 
sequence (dred_0137 to dred_0141 and dred_0143 to dred_0148) separated by a gene encoding a protein of unknown function (dred_0142).

In two loci (II and IV), the presence of all three subunits of $\mathrm{Hdr}(\mathrm{HdrABC})$ along with the delta subunit of an Mvh (a [NiFe] $\mathrm{H}_{2}$ ase) is reminiscent of the Mvh : Hdr complex in the methanogen Methanothermobacter thermoautotrophicus (Setzke et al., 1994). This complex is thought to transfer electrons from $\mathrm{H}_{2}$ to an electron acceptor interacting with the Hdr (Mander et al., 2004). The main difference between the methanogen and $D$. reducens is the absence of the other subunits of Mvh : Methanothermobacter marburgensis has three (Stojanowic et al., 2003), including two (MvhA and MvhG) that correspond to hydrogenase modules conserved in all [NiFe] $\mathrm{H}_{2}$ ases, but $D$. reducens only has the delta subunit (MvhD) that is unique to Mvh (Table S1). The delta subunit has been implicated in the transfer of electrons from Mvh to Hdr (Stojanowic et al., 2003). By analogy, electrons derived from a soluble cytoplasmic protein could be transferred to MvhD and on to HdrA (locus I) or HdrABC (locus IV) and to the APS reductase (Fig. 2).

Locus $\mathrm{V}$ combines the 4-TMH membrane-spanning $h d r F$ (dred_1777) with electron-transfer flavoproteins (dred_1778-9) and an hdrD subunit (dred_1783) (Fig. 5). It is reminiscent of $\mathrm{HdrDE}$ in Methanosarcina barkeri (Heiden et al., 1994) but lacks HdrE, the membraneanchoring b-type cytochrome. In Methanosarcina mazei, this complex is a proton pump that is part of the electron transport chain and receives electrons from hydroxyphenazine and uses them to reduce the CoenzymeMCoenzymeB complex (Ide et al., 1999; Baumer et al., 2000). In $D$. reducens, the membrane-spanning domain pertains to $\mathrm{HdrF}$ and it is likely that this subunit receives electrons from the quinone pool and passes them on to the electron-transfer flavoproteins (Fig. 2). It is also possible that proton-translocation occurs during the electron transfer (Fig. 2).

If the current proposed scheme for sulfate reduction in D. reducens (Fig. 2) is confirmed, it would represent a significant departure from the accepted model of 'redox cycling' for sulfate reduction by Gram-negative SRB. In the proposed scheme (shown in red in Fig. 2), electrons from electron donors (such as lactate or butyrate) would be transferred to the Qmo complex from intermediate electron-carrying proteins such as heterodisulfide reductase and/or electron transfer flavoproteins, and Qmo would pass the electrons on to APS reductase, which in turn, would reduce APS to sulfite. Electrons could also be transferred from electron donors to electron-carrying compounds such as $\mathrm{H}_{2}$, formate and $\mathrm{NADH}$. Those electrons would be transferred to the quinone pool by proteins such as the membrane-bound hydrogenase, formate $\mathrm{DH}$ and NADH DH. From the quinone pool, elec- trons could be transferred to the DsrC subunit of the sulfite reductase via the DsrMK complex and sulfite reduced to sulfide. The generation of a proton motive force, which relies on the presence of periplasmic $\mathrm{H}_{2}$ in Gram-negative bacteria, would occur via the translocation of protons through pyropohosphatase, formate $\mathrm{DH}$, membrane-bound $\mathrm{H}_{2}$ ase, the quinone pool as well as $\mathrm{NADH} \mathrm{DH}$. Given that many of the proteins proposed to be involved in sulfate reduction in $D$. reducens have homologues in the other sequenced Gram-positive SRB (i.e., pyrophosphatase, DsrMK, QmoAB, HdrABC, MvhD), D. reducens may serve as a model for sulfate reduction in Gram-positive SRB.

\section{Hydrogen metabolism}

In general, the consumption and the evolution of $\mathrm{H}_{2}$ are mediated by hydrogenases $\left(\mathrm{H}_{2}\right.$ ases $)$, redox metalloenzymes that catalyse the reversible reaction $\mathrm{H}_{2} \leftrightarrow 2 \mathrm{H}^{+}+2 \mathrm{e}^{-}$(Vignais et al., 2001; Vignais and Colbeau, 2004; Meyer, 2007). These enzymes have been classified as either [FeFe], [NiFe] or [NiFeSe] $\mathrm{H}_{2}$ ases according to the composition of their metal sites.

The $D$. reducens genome encodes six hydrogenases (Table 2). This number of hydrogenases is comparable with that in the genomes of organisms that, in contrast to D. reducens, are able to conserve energy by using $\mathrm{H}_{2}$ as a source of electrons. For instance, the genome of $D v$. vulgaris in which sulfate reduction depends on $\mathrm{H}_{2}$ oxidation encodes six hydrogenases (Heidelberg et al., 2004), and that of Geobacter sulfurreducens, which is able to couple $\mathrm{H}_{2}$ oxidation to growth with $\mathrm{Fe}(\mathrm{III})$ as an electron acceptor, has four (Methe et al., 2003). All six $\mathrm{H}_{2}$ ases in D. reducens are Fe-containing hydrogenases and four of them are encoded by multi-locus operons and represent trimeric $\mathrm{H}_{2}$ ases (Table 2). The other two (dred_1440 and dred_1794) are single-gene hydrogenases.

Trimeric Fe-containing $\mathrm{H}_{2}$ ases. Three (dred_3290-92, dred_1651-53 and dred_1654-56) of the four multimeric [FeFe] $\mathrm{H}_{2}$ ases are cytoplasmic, trimeric hydrogenases composed of a catalytic subunit and two additional subunits and are encoded by non-identical copies of the operon. The genes encoding the catalytic subunit (dred_3290,dred_1651 and dred_1654) contain several FeS binding sites in addition to the active site. The additional subunits are homologous to two peripheral subunits of $\mathrm{NADH}$-ubiquinone oxidoreductase, indicating that these are $\operatorname{NAD}(\mathrm{P})(\mathrm{H})$ dependent $\mathrm{H}_{2}$ ases. These trimeric hydrogenases resemble the $\mathrm{H}_{2}$-evolving [FeFe] $\mathrm{H}_{2}$ ases of the hyperthermophilic bacterium Thermotoga maritima that is able to grow by fermenting carbohydrates (Verhagen et al., 1999). The three $\mathrm{H}_{2}$ ases were found to be upregulated during sulfate reduction with lactate as an 
Table 2. List of hydrogenases identified in the $D$. reducens genome, their characteristics and their expression level during pyruvate fermentation or lactate-dependent sulfate reduction.

\begin{tabular}{|c|c|c|c|c|c|c|c|}
\hline \multirow[b]{2}{*}{ Locus dred_ } & \multirow[b]{2}{*}{ Product name } & \multirow[b]{2}{*}{ Type } & \multirow[b]{2}{*}{ Organization } & \multirow[b]{2}{*}{ Localization } & \multirow[b]{2}{*}{ Size (aa) } & \multicolumn{2}{|c|}{ Expression level } \\
\hline & & & & & & Fermentation & Respiration \\
\hline 1440 & Hydrogenase & $\mathrm{FeFe}$ & Monomeric & Unknown & 429 & $0.63 \pm 0.19$ & $1.47 \pm 0.61$ \\
\hline 1794 & Hydrogenase & $\mathrm{FeFe}$ & Monomeric & Unknown & 462 & $3.37 \pm 0.24$ & $0.35 \pm 0.03$ \\
\hline 0461 & Hydrogenase & $\mathrm{FeFe}$ & Trimeric & Membrane-bound & 381 & $0.94 \pm 0.20$ & $1.02 \pm 0.04$ \\
\hline 0462 & & & & & 261 & $1.14 \pm 0.17$ & $0.95 \pm 0.06$ \\
\hline $0463^{a}$ & & & & & 520 & $1.39 \pm 0.12$ & $0.97 \pm 0.03$ \\
\hline $1651^{a}$ & Hydrogenase & $\mathrm{FeFe}$ & Trimeric & Cytoplasmic & 593 & $0.16 \pm 0.09$ & $1.88 \pm 0.10$ \\
\hline 1652 & & & & & 569 & $0.12 \pm 0.08$ & $2.06 \pm 0.09$ \\
\hline 1653 & & & & & 158 & $0.12 \pm 0.06$ & $2.34 \pm 0.07$ \\
\hline $1654^{a}$ & Hydrogenase & $\mathrm{FeFe}$ & Trimeric & Cytoplasmic & 659 & $0.48 \pm 0.06$ & $19.75 \pm 0.79$ \\
\hline 1655 & & & & & 627 & $0.47 \pm 0.16$ & $12.76 \pm 0.74$ \\
\hline 1656 & & & & & 163 & $0.42 \pm 0.10$ & $11.09 \pm 0.47$ \\
\hline $3290^{a}$ & Hydrogenase & $\mathrm{FeFe}$ & Trimeric & Cytoplasmic & 594 & $0.39 \pm 0.02$ & $2.16 \pm 0.54$ \\
\hline 3291 & & & & & 575 & $0.09 \pm 0.02$ & $3.06 \pm 1.05$ \\
\hline 3292 & & & & & 177 & $0.11 \pm 0.02$ & $2.97 \pm 1.08$ \\
\hline
\end{tabular}

a. Indicates the catalytic domain-containing subunit in trimeric hydrogenases.

electron donor but not during pyruvate fermentation (Table 2), suggesting that $\mathrm{H}_{2}$ production may be mediated by these trimeric $[\mathrm{FeFe}] \mathrm{H}_{2}$ ases and coupled to $\mathrm{H}_{2}$ consumption (no $\mathrm{H}_{2}$ is detected in the medium) during lactate oxidation.

The fourth trimeric [FeFe] hydrogenase (dred_0461-3) is membrane-bound and is encoded by an operon that includes a FeS-cluster-containing component (dred_ 0462) and a putative hydrogenase cytochrome $b$ subunit (dred_0461) that is predicted to contain ten transmembrane helices. This $\mathrm{H}_{2}$ ase is homologous to a potentially $\mathrm{H}_{2}$-consuming hydrogenase in Desulfitobacterium hafniense Y51 (Nonaka et al., 2006). Thus, this $\mathrm{H}_{2}$ ase could be involved in the transfer of electrons from $\mathrm{H}_{2}$ to the quinone pool and - by virtue of its membrane localization - transfer protons to the outside (Fig. 2).

Monomeric Fe-containing $\mathrm{H}_{2}$ ases. These two $\mathrm{H}_{2}$ ases (dred_1440 and dred_1794) are upregulated (Table 2) either during pyruvate fermentation (dred_1794), suggesting the evolution of $\mathrm{H}_{2}$, or during sulfate reduction (dred_1440) suggesting the consumption of $\mathrm{H}_{2}$.

Phylogenetic study of the catalytic subunit. A phylogenetic study of the catalytic subunit of the six [FeFe] hydrogenases (Fig. 6) reveals that there are two major clusters. One corresponds to fast-evolving hydrogenases (the branches are long and there is more evolutionary distance between adjacent species) and the other to slow-evolving hydrogenases (shorter branches with less evolutionary distance between adjacent species). It is readily apparent that the trimeric $\mathrm{H}_{2}$ ases are in the slow-evolving branch whereas their monomeric counterparts are in the fastevolving branch. This is consistent with the need for evolution in concert of the three subunits for the trimeric case whereas the monomeric $\mathrm{H}_{2}$ ases can evolve independently.

The overall picture that emerges from the above sections is that the trimeric cytoplasmic $[\mathrm{FeFe}] \mathrm{H}_{2}$ ases are responsible for the production of $\mathrm{H}_{2}$ during sulfate reduction, the trimeric [ $\mathrm{FeFe}$ ] membrane-spanning $\mathrm{H}_{2}$ ase consumes $\mathrm{H}_{2}$ and translocates $\mathrm{H}^{+}$and the monomeric [FeFe] $\mathrm{H}_{2}$ ases either produce (dred_1794) or consume (dred_1440) $\mathrm{H}_{2}$.

\section{Metal reduction}

Vegetative cells of $D$. reducens are able to reduce soluble $\mathrm{Fe}(\mathrm{III})$ with pyruvate, lactate or butyrate but not $\mathrm{H}_{2}$ as an electron donor, in a process that supports growth (Fig. S7). This is an unusual ability in SRB as there are only four other SRB known to couple Fe(III) reduction to growth: D. psychrophila (Knoblauch et al., 1999), Desulfosporosinus lacus (Ramamoorthy et al., 2006), Desulfosporomusa polytropa (Sass et al., 2004) and Desulfobulbus propionicus (Holmes et al., 2004). Furthermore, vegetative cell suspensions (Tebo and Obraztsova, 1998) as well as spores (Junier et al., 2009) of $D$. reducens were shown to reduce $\mathrm{U}(\mathrm{VI})$ with butyrate and $\mathrm{H}_{2}$ as an electron donor, respectively.

The biochemical mechanism of microbially mediated iron reduction has been studied in some detail in two bacterial genera: Geobacter and Shewanella. In Geobacter spp., direct contact between $\mathrm{Fe}(\mathrm{III})$ oxides and bacterial cells is required and the production of conductive 'nanowires' facilitates the transfer of electrons to the solid phase (Reguera et al., 2005). The transfer of electrons from the NADH dehydrogenase to the terminal electron acceptor during iron catabolism requires five c-type cytochromes and a type IV pilus (Weber et al., 2006). 




Fig. 6. Neighbour-joining phylogenetic tree of Fe-only hydrogenases based on aligments of the $\mathrm{H}$ cluster domain. Clades consisting entirely of the same genus were condensed to a single leaf. The branches corresponding to the different Fe-only hydrogenase genes in Desulfotomaculum reducens are boxed in blue for trimeric hydrogenases and in red for monomeric hydrogenases.

Shewanella oneidensis MR-1 also produces conductive appendages (Gorby et al., 2006) and also requires c-type cytochromes for soluble and insoluble $\mathrm{Fe}(\mathrm{III})$ reduction (Beliaev et al., 2001). In addition, the use of endogenous and exogenous soluble extracellular electron shuttles has been well documented to mediate the reduction of
$\mathrm{Fe}$ (III)-oxides in both genera (Newman and Kolter, 2000; Nevin and Lovley, 2002).

As for microbial $\mathrm{U}(\mathrm{VI})$ reduction, in $\mathrm{S}$. oneidensis, the pathways for iron and $\mathrm{U}(\mathrm{VI})$ reduction are similar and involve several $c$-type cytochromes (Beliaev et al., 2001; Bencheikh-Latmani et al., 2005). U(VI) reduction in G. 
sulfurreducens involves other c-type cytochromes than those involved in $\mathrm{Fe}(\mathrm{III})$ reduction (Shelobolina et al., 2007).

In contrast, the genome of $D$. reducens is strikingly cytochrome-poor. The only $c$-type cytochrome present is a triheme cytochrome $c_{552}$ that is encoded by two genes (dred_0700 and dred_0701). This is an integral membrane $c$-type cytochrome annotated as the two-subunit nitrite reductase ( $\mathrm{NrfHA})$. This protein is likely to transfer electrons from the quinone pool to an unidentified cytoplasmic or extracellular electron acceptor. Evidence for such a process rests in the small subunit $(\mathrm{NrfH})$ that is predicted (via BLAST analysis) to interact with menaquinol. Even though $\mathrm{NrfHA}$ is annotated as a nitrite reductase, it is unlikely to be involved in nitrite reduction. Analysis of mRNA from a $D$. reducens culture amended with nitrite during sulfate reduction shows that this gene has a higher qualitative level of expression in the absence than in the presence of nitrite (Fig. 7C). This is in sharp contrast to the effect of nitrite on the expression of the physiological nitrite reductase in $D v$. vulgaris for which genes encoding nitrite reductase were highly upregulated (Haveman et al., 2004). Thus, the low nitrite reduction activity observed could be due to the sulfite reductase that is known to have some nitrite reductase activity in $D v$. vulgaris (Haveman et al., 2004). We hypothesize that, in $D$. reducens, NrfHA may play a role in electron transfer directly, or indirectly via the quinone pool, to electron acceptors other than nitrite, for example U(VI) (shown in blue, Fig. 2) or soluble Fe(III).

Inspection of electron micrographs of $D$. reducens after $\mathrm{U}(\mathrm{VI})$ reduction suggests that the process is associated with the cell wall because the accumulation of $U(I V)$ occurs both inside and outside the cell membrane (Fig. 8). $\mathrm{NrfHA}$ is an outside-facing, transmembrane $c$-type cytochrome. Due to its localization, we hypothesize that this protein may be involved in $\mathrm{U}(\mathrm{VI})$ reduction.

Several studies have considered $\mathrm{U}(\mathrm{VI})$ and $\mathrm{Fe}(\mathrm{III})$ reduction by the two SRB $D v$. vulgaris and $D v$. desulfuricans. The mechanism of reduction was found to involve both periplasmic (Payne et al., 2002) and cytoplasmic ( $\mathrm{Li}$ and Krumholz, 2009) proteins. Uranium reduction in $D v$. desulfuricans with $\mathrm{H}_{2}$ as an electron donor was found to involve the transfer of electrons from a periplasmic hydrogenase via the periplasmic $c_{3}$ cytochromes to $\mathrm{U}(\mathrm{VI})$ (Payne et al., 2002). In Dv. vulgaris Hildenborough, Fe(III) and $\mathrm{U}(\mathrm{VI})$ reduction was found to also involve periplasmic $\mathrm{H}_{2}$ ases and $c_{3}$-type cytochromes (Elias et al., 2004). A more recent study has shown that it is a periplasmic [FeFe] $\mathrm{H}_{2}$ ase, not a [NiFe] $\mathrm{H}_{2}$ ase, that is involved in the reduction of soluble Fe(III) (Park et al., 2008). By analogy, the $\mathrm{H}_{2}$-consuming, membrane-bound [FeFe] hydrogenase in $D$. reducens (Table 2) could be involved in $\mathrm{U}(\mathrm{VI})$ reduction. Paralleling the mechanism described in Des-


Fig. 7. Effect of nitrite on growth of and sulfate reduction by $D$. reducens.

A. Cell growth as $\mathrm{OD}_{600}$ (closed symbols and solid lines) sulfate (closed symbols and dashed lines) and nitrite (open symbols and dashed lines) reduction. The addition of $0.1 \mathrm{mM}$ nitrite inhibits growth and sulfate reduction, but the cells recover after nitrite is removed from solution. In contrast, $0.2 \mathrm{mM}$ nitrite shuts down growth and sulfate reduction.

B. Nitrite reductase operon.

C. Reverse transcription PCR results for dsrAB and nrfHA after addition of nitrite. NrfA is expressed in the absence of nitrite but to a lesser extent in its presence. $\mathrm{NrfH}$ is not detectable in any of the cases considered.

ulfovibrio spp., the hydrogenase could be transferring electrons from $\mathrm{H}_{2}$ to the $c$-type cytochrome $\mathrm{NrfHA}$, which would serve as the terminal reductase (shown in blue, Fig. 2).

In addition to the $\mathrm{H}_{2}$ ases, a cytoplasmic thioredoxin, a thioredoxin reductase and associated oxidoreductase were found to participate in $\mathrm{U}(\mathrm{VI})$ reduction in the cytoplasm of Dv. desulfuricans G20 (Li and Krumholz, 2009). In an effort to determine whether a similar mechanism could be involved in $D$. reducens, we evaluated the pres- 




Fig. 8. Electron micrograph of thin sections of a $D$. reducens culture grown fermentatively with pyruvate in the presence of $100 \mu \mathrm{M} U(\mathrm{VI})$ and stained with Sato lead. Scale bar is $1 \mu \mathrm{m}$.

ence of thioredoxins in its genome. There are three ORFs annotated as thioredoxins in the $D$. reducens genome (dred_0762, dred_0904 and dred_2669), but only one (dred_2669) is associated with a thioredoxin reductase (dred_2670). A third gene (dred_2668) that includes nine $\mathrm{TMH}$ and has no known function is present as part of this apparent operon. This thioredoxin could possibly be involved in $\mathrm{U}(\mathrm{VI})$ reduction, but no direct evidence for this is available at the present time.

\section{Conclusions}

Desulfotomaculum reducens is one of two cultivated Gram-positive SRB for which a complete genome is available. Due to the absence of a periplasm, the mechanism of sulfate-reduction in this SRB does not correspond to that identified in Desulfovibrio vulgaris and likely involves the transfer of electrons directly from the quinone pool to the DsrMK complex and to the sulfite reductase (DsrABC). In addition, it is proposed that the cytoplasmic QmoAB complex transfers electrons from cytoplasmic proteins to the APS reductase. Other proteins such as heterodisulfide reductases and electron-transfer flavoproteins are likely involved in electron transfer and we propose that they may provide electrons to the Qmo complex. However, a detailed mechanism cannot be surmised by genome analysis. Finally, a number of proton- translocating transmembrane proteins - notably a pyrophosphatase conserved in all four Gram-positive SRB sequenced to date - suggest the production of a proton motive force without periplasmic oxidation of $\mathrm{H}_{2}$. Because many of the proteins involved in the $D$. reducens-specific sulfate-reduction pathway have homologues in the genomes of other Gram-positive SRB, $D$. reducens may represent a good model for sulfatereduction in Gram-positive SRB.

\section{Experimental procedures}

\section{DNA extraction and purification}

Genomic DNA was extracted from an overnight culture of $D$. reducens that was grown in Widdel medium (Widdel and Bak, $1992)$ with sulfate $(10 \mathrm{mM})$ as an electron acceptor and lactate $(20 \mathrm{mM})$ as an electron donor. DNA extraction was carried out using CTAB (hexadecyltrimethyl ammonium bromide). The cells were treated with $100 \mathrm{mg} \mathrm{ml}^{-1}$ lysozyme, followed by proteinase $\mathrm{K}\left(10 \mathrm{mg} \mathrm{ml}^{-1}\right)$ and the product amended with a solution of $0.3 \mathrm{M} \mathrm{CTAB}$ and $0.7 \mathrm{M} \mathrm{NaCl}$ and a chloroform:isoamyl alcohol (24:1) solution. After centrifugation of the mixture, the supernatant was transferred to a new tube and amended with a phenol:chloroform:isoamyl alcohol (25:24:1) solution. After a second centrifugation, the supernatant was transferred and the DNA precipitated with isopropanol. A final treatment with RNAse A (Qiagen, Valencia, CA) was used to remove residual RNA.

\section{Sequencing}

The genome of $D$. reducens $\mathrm{Ml}-1$ was sequenced at the Joint Genome Institute (JGl) using a combination of $3 \mathrm{~kb}, 8 \mathrm{~kb}$ and $40 \mathrm{~kb}$ (fosmid) DNA libraries. All general aspects of library construction and sequencing performed at the JGI can be found at http://www.jgi.doe.gov/. Draft assemblies were based on 40920 total reads. All three libraries provided 11x coverage of the genome. The Phred/Phrap/Consed software package (http://www.phrap.com) was used for sequence assembly and quality assessment (Ewing and Green, 1998; Ewing et al., 1998; Gordon et al., 1998). After the shotgun stage, reads were assembled with parallel phrap (High Performance Software, LLC). Possible mis-assemblies were corrected with Dupfinisher (Han and Chain, 2006) or transposon bombing of bridging clones (Epicentre Biotechnologies, Madison, WI, USA). Gaps between contigs were closed by editing in Consed, custom primer walk or PCR amplification (Roche Applied Science, Indianapolis, IN, USA). A total of 2634 additional reactions were necessary to close gaps and to raise the quality of the finished sequence. The completed genome sequences of $D$. reducens contains 43940 reads, achieving an average of 12 -fold sequence coverage per base with an error rate less than 1 in 100000.

\section{Annotation}

Genes were identified using a combination of Critica (Badger and Olsen, 1999) and Glimmer (Delcher et al., 1999), fol- 
lowed by a round of manual curation, which resulted in adjustments of the start codons and insertion of missed genes and pseudogenes. tRNAs were predicted using the tRNAScan-SE tool (Lowe and Eddy, 1997). Automatic product name assignment was made based on the results obtained from searches against curated databases. Signal peptides were identified using the SignalP 3.0 (Bendtsen et al., 2004) and TMHMM (Krogh et al., 2001) at default values. Manual curation of the automatic annotation occurred within the IMG-ER (http://merced.jgi-psf.org/cgibin/er/main.cgi) system. The sequence data described here have been deposited in GenBank (CP000612).

\section{Phylogenetic analysis of Fe-Fe hydrogenases}

The hydrogenase phylogeny was based on the $\mathrm{H}$ cluster, which is shared by all members of the hydrogenase family (Vignais et al., 2001). The position of the $\mathrm{H}$ cluster in one sequence was determined by scanning for Pfam PF02906 $(\mathrm{H}$ cluster) with Prosite. The sequences were then aligned with Muscle (Edgar, 2004), and the alignment was trimmed so as to keep only the $\mathrm{H}$ cluster. A phylogenetic tree was then constructed using BioNJ (Gascuel, 1997), using a eukaryote (Culex quinquefasciatus) as an outgroup. Clades consisting entirely of the same genus were condensed to a single leaf.

\section{Nitrite reduction as a detoxification strategy}

To test nitrite reduction, a culture was grown in WLP medium supplemented with yeast extract, $0.05 \%$; $\mathrm{NaHCO}_{3}, 30 \mathrm{mM}$; 1,4-piperazinediethane sulfonic acid disodium salt monohydrate (PIPES), $20 \mathrm{mM}$; sodium sulfate, $10 \mathrm{mM}$, lactic acid $20 \mathrm{mM}$. The culture was incubated for $9.5 \mathrm{~h}$ until the onset of growth and sulfate reduction. Aliquots of the culture $(20 \mathrm{ml})$ were transferred to $50 \mathrm{ml}$ serum bottles previously flushed with $\mathrm{N}_{2}$. The cultures were then supplemented with $0,0.1$ or $0.2 \mathrm{mM}$ of sodium nitrite. Growth was quantified by measuring optical density at $600 \mathrm{~nm}$. Samples for $\mathrm{SO}_{4}{ }^{2-}$ and $\mathrm{NO}_{2}{ }^{-}$ were collected, filtered (PVDF $0.2 \mu \mathrm{m}$ filters) and analysed by ion chromatography (DX-500, Dionex, Sunnyvale, CA, USA) using an IonPac AS12A column and a bicarbonate (30 mM) eluent. A sample for RNA extraction was collected at $3.5 \mathrm{~h}$ of incubation after the addition of nitrite. RNA was extracted using the RNAeasy Qiagen Kit with on-column DNAse treatment. The quantity and quality of the RNA were evaluated with a Nanodrop spectrophotometer (Thermo Scientific). Reverse transcription PCR (RT-PCR) was carried out for the following genes: $16 \mathrm{~S}$ rRNA, nrfH and nrfA. For RT-PCR primers specific for $D$. reducens were designed using PrimerBLAST: 16 S rRNA, DR140 (5'-TAG ACC GGG ATA ACA GCT G-3') and DR842 (5'-ATA CCC GCA ACA CCT AGC AC-3'); $n r f H$, nrfHF (5'- CAT TAT GGA TCC CTG GGT TG $\left.-3^{\prime}\right)$ and nrfHR (5'-GTC CTG ACC ACG GTC ATT CT-3'), and nrfA, nrfAF (5'-AGC CCC GGA GTC ACT TTT AT-3') and nrfAR (5'-CAT GAC ACT GGG CAC ATA CC-3'). First-strand synthesis was carried out using SuperScript III from Invitrogen. PCR was carried out using NEB Taq DNA polymerase.

\section{Hydrogenase expression data}

For expression analysis Widdel medium was used. The medium was dispensed $(100 \mathrm{ml})$ into $200 \mathrm{ml}$ glass serum bottles and autoclaved. The following solutions were added from sterile anaerobic stocks (final concentration): yeast extract, $0.05 \%$; $\mathrm{NaHCO}_{3}, 30 \mathrm{mM} ;$ 1,4-piperazinediethane sulfonic acid disodium salt monohydrate (PIPES), $20 \mathrm{mM}$. For fermentative growth only $20 \mathrm{mM}$ of pyruvic acid was added to the medium. For sulfate respiration $20 \mathrm{mM}$ sulfate (as sodium sulfate) and $20 \mathrm{mM}$ lactic acid were included in the medium. The final $\mathrm{pH}$ of the medium was $7.2 \pm 0.2$. Growth in the cultures was monitored by $\mathrm{OD}_{600}$. The experiments were run in four biological replicates. The cultures were sampled $(16 \mathrm{ml})$ for RNA extraction at mid-exponential phase. Samples were collected in an RNAse-free $50 \mathrm{ml}$ Falcon tube by centrifugation at $7000 \mathrm{~g}$ for $7 \mathrm{~min}$ and resuspended in $400 \mu \mathrm{l}$ of $3 \mathrm{mg} \mathrm{ml}^{-1}$ lysozyme in TE buffer $(\mathrm{pH}$ 8.0) and mixed by vortexing. After digestion for $10 \mathrm{~min}$ at room temperature, $1.4 \mathrm{ml}$ of Buffer RLT (Qiagen) containing freshly added $0.01 \% \mathrm{v} / \mathrm{v} \beta$-mercaptoethanol was added to the sample and mixed vigorously by vortexing. The homogenized cell lysates were stored at $-80^{\circ} \mathrm{C}$. After all the samples were collected, the cell lysates were thawed for $15 \mathrm{~min}$ at $37^{\circ} \mathrm{C}$ in a water bath to dissolve salts. The samples were separated into four equal aliquots of $450 \mu \mathrm{l}$. RNA extraction was carried out as described above. RNA from the four aliquots was combined and precipitated using 0.1 volume of $1 \mathrm{M}$ sodium acetate and 2.5 volume cold $95 \%$ ethanol and incubated over-night at $-20^{\circ} \mathrm{C}$. RNA was collected by centrifugation for $15 \mathrm{~min}$ at $12000 \mathrm{~g}$ at $4^{\circ} \mathrm{C}$ and washed with $75 \%$ ethanol. RNA was dried at $37^{\circ} \mathrm{C}$ for $20 \mathrm{~min}$ and resuspended in $30 \mu \mathrm{l}$ RNAse-free water. RNA concentration and quality were re-measured using the Nanodrop and the Bioanalyzer (Agilent). A total of $20 \mu \mathrm{g}$ of RNA per sample was sent to Nimblegen Roche for cDNA synthesis and hybridization onto custom-designed $4 \times 77 \mathrm{~K}$ microarrays. Normalized RMA signals were used for the analysis using the software GeneSpring GX v7.3. Per gene normalization was applied when the data were loaded into a customized one-colour experiment in the analysis software. Expression data were extracted using the option 'advanced find gene'. Average values were calculated from the four biological replicates.

\section{Electron microscopy}

Samples for electron microscopy were prepared by fixing the cells in gluteraldehyde and dehydrating them sequentially in pure grade Ethanol (Fluka). The fixed dehydrated cells were then pelleted and immobilized in LR-white resin (EMS, Hatfield, PA, USA) that was polymerized at $60^{\circ} \mathrm{C}$. This procedure was carried out inside an anaerobic chamber to prevent sample oxidation. Thin sections of the resin were cut using a microtome, placed on copper grids (Quantifoil Micro Tools $\mathrm{GmbH}$, Jena) and stained with Sato lead. The samples were observed in a FEI CM20 microscope (Eindhoven, Netherlands). Images were recorded on a Gatan 797 slow scan CCD camera (1024 pixels $\times 1024$ pixels $\times 14$ bits) and processed with the Gatan Digital Micrograph 3.11.0 software (Gatan, Pleasanton, CA, USA).

Access to the genome is provided by the DOE Joint Genome Institute (JGI) at the Integrated Microbial Genome (IMG) site: http://img.jgi.doe.gov/cgi-bin/pub/main.cgi 


\section{Acknowledgements}

We acknowledge funding from the Swiss National Science Foundation through Grant No. 33100A0-112337. In addition, this publication was made possible by grant number ES010337 from the National Institute of Environmental Health Sciences (NIEHS), NIH. Its contents are solely the responsibility of the authors and do not necessarily represent the official views of the NIEHS, NIH. The work conducted by the US Department of Energy Joint Genome Institute is supported by the Office of Science of the US Department of Energy under contract No. DE-AC02-05CH11231. T.G.'s contributions to computational aspects of this work were supported in part by the US National Science Foundation grant number 0626678. Finally, we thank three anonymous reviewers whose constructive comments lead to a marked improvement of this manuscript.

\section{References}

Badger, J.H., and Olsen, G.J. (1999) CRITICA: coding region identification tool invoking comparative analysis. Mol Biol Evol 16: 512-524.

Baumer, S., Ide, T., Jacobi, C., Johann, A., Gottachalk, G., and Deppenmeier, U. (2000) The F420-H2 dehydrogenase from Methanosarcina mazei is a redox-driven proton pump closely related to NADH dehydrogenases. J Biol Chem 275: 17968-17973.

Beliaev, A.S., Saffarini, D.A., McLaughlin, J.L., and Hunnicutt, D. (2001) MtrC, an outer membrane decahaem $c$ cytochrome required for metal reduction in Shewanella putrefaciens MR-1. Mol Microbiol 39: 722-730.

Bencheikh-Latmani, R., Williams, S.M., Haucke, L., Criddle, C.S., Wu, L., Zhou, J., and Tebo, B.M. (2005) Global Transcriptional Profiling of Shewanella oneidensis MR-1 During $\mathrm{Cr}(\mathrm{VI})$ and $\mathrm{U}(\mathrm{VI})$ Reduction. Appl Environ Microbiol 71: 7453-7460.

Bendtsen, J.D., Nielsen, H., von Heijne, G., and Brunak, S. (2004) Improved prediction of signal peptides: signalP 3.0. $\checkmark$ Mol Biol 340: 783-795.

Chang, Y., Peacock, A.D., Long, P., Stephen, J.R., McKinley, J.P., Macnaughton, S.J., et al. (2001) Diversity and characterization of sulfate-reducing bacteria in groundwater at a uranium mill tailings site. Appl Environ Microbiol 67: 3149-3160.

Chivian, D., Brodie, E.L., Alm, E.J., Culley, D.E., Dehal, P.S., DeSantis, T.Z., et al. (2008) Environmental genomics reveals a single-species ecosystem deep within earth. Science 322: 275-278.

Delcher, A.L., Harmon, D., Kasif, S., White, O., and Salzberg, S.L. (1999) Improved microbial gene identification with GLIMMER. Nucleic Acids Res 27: 4636-4641.

Edgar, R.C. (2004) MUSCLE: multiple sequence alignment with high accuracy and high throughput. Nucleic Acids Res 32: 1792-1797.

Elias, D.A., Krumholz, L.R., Wong, D., Long, P.E., and Suflita, J.M. (2003) Characterization of microbial activities and $U$ reduction in a shallow aquifer contaminated by uranium mill tailings. Microb Ecol 46: 83-91.

Elias, D.A., Suflita, J.M., McInerney, M.J., and Krumholz, L.R. (2004) Periplasmic cytochrome $C_{3}$ of Desulfovibrio vulgaris is directly involved in $\mathrm{H}_{2}$-mediated metal but not sulfate reduction. Appl Environ Microbiol 70: 413-420.

Ewing, B., and Green, P. (1998) Base-calling of automated sequencer traces using phred. II. Error probabilities. Genome Res 8: 186-194.

Ewing, B., Hillier, L., Wendl, M.C., and Green, P. (1998) Base-calling of automated sequencer traces using phred. I. Accuracy assessment. Genome Res 8: 175-185.

Gascuel, O. (1997) BIONJ: an improved version of the $\mathrm{NJ}$ algorithm based on a simple model of sequence data. $\mathrm{Mol}$ Biol Evol 14: 685-695.

Gorby, Y.A., Yanina, S., McLean, J.S., Rosso, K.M., Moyles, D., Dohnalkova, A., et al. (2006) Electrically conductive bacterial nanowires produced by Shewanella oneidensis strain MR-1 and other microorganisms. Proc Natl Acad Sci USA 103: 11358-11363.

Gordon, D., Abajian, C., and Green, P. (1998) Consed: a graphical tool for sequence finishing. Genome Res 8: 195202.

Han, C.S., and Chain, P. (2006) Finishing repeat regions automatically with Dupfinisher. In Proceedings of 2006 International Conference on Bioinformatics \& Computational Biology. Arabnia, H.R., and Valafar, H. (eds). Las Vegas, NV, USA: CSREA Press, pp. 141-146.

Haveman, S.A., Greene, E.A., Stilwell, C.P., Voordouw, J.K., and Voordouw, G. (2004) Physiological and gene expression analysis of inhibition of Desulfovibrio vulgaris Hildenborough by nitrite. J Bacteriol 186: 7944-7950.

Heidelberg, J.F., Seshadri, R., Haveman, S.A., Hemme, C.L., Paulsen, I.T., Kolonay, J.F., et al. (2004) The genome sequence of the anaerobic, sulfate-reducing bacterium Desulfovibrio vulgaris Hildenborough. Nat Biotechnol 22: 554-559.

Heiden, S., Hedderich, R., Setzke, E., and Thauer, R.K. (1994) Purification of a two-subunit cytochrome-bcontaining heterodisulfide reductase from methanol-grown Methanosarcina barkeri. Eur J Biochem 221: 855-861.

Holmes, D.E., Bond, D.R., and Lovley, D.R. (2004) Electron transfer by Desulfobulbus propionicus to $\mathrm{Fe}(\mathrm{III})$ and graphite electrodes. Appl Environ Microbiol 70: 1234-1237.

Ide, T., Baumer, S., and Deppenmeier, U. (1999) Energyconvservation by the $\mathrm{H} 2$ :heterodisulfide oxidoreductase from Methanosarcina mazei Go1: identification of two proton-translocating segments. J Bacteriol 181: 40764080 .

Ishii, K., Takii, S., Fukunaga, S., and Aoki, K. (2000) Characterization by denaturing gradient gel electrophoresis of bacterial communities in deep groundwater at the Kamaishi Mine, Japan. J Gen Appl Microbiol 46: 85-93.

Junier, P., Frutschi, M., Wigginton, N.S., Schofield, E.J., Bargar, J.R., and Bernier-Latmani, R. (2009) Metal reduction by spores of Desulfotomaculum reducens. Environ Microbiol 11: 3007-3017.

Junier, P., Suvorova, E.I., and Bernier-Latmani, R. (2010) Effect of competing electron acceptors on the reduction of $\mathrm{U}(\mathrm{VI})$ by Desulfotomaculum reducens Geomicrobiol $J$ (in press).

Knoblauch, C., Sahm, K., and Jorgensen, B.B. (1999) Psychrophilic sulfate-reducing bacteria isolated from permanently cold Arctic marine sediments: description of Desulfofrigrus oceanense gen. nov., sp nov., Desulfofrigus 
fragile sp nov., Desulfofaba gelida gen. nov., sp nov., Desulfotalea psychrophila gen. nov., sp nov and Desulfotalea arctica sp nov. Int J Syst Bacteriol 49: 1631-1643.

Kremer, D.R., Veenhuis, M., Fauque, G., Peck, H.D., Legall, J., Lampreia, J., et al. (1988) Immunocytochemical localization of APS reductase and bisulfite reductase in three Desulfovibrio species. Arch Microbiol 150: 296-301.

Krogh, A., Larsson, B., von Heijne, G., and Sonnhammer, E.L.L. (2001) Predicting transmembrane protein topology with a hidden Markov model: application to complete genomes. J Mol Biol 305: 567-580.

Li, X., and Krumholz, L.R. (2009) Thioredoxin is involved in $\mathrm{U}(\mathrm{VI})$ and $\mathrm{Cr}(\mathrm{VI})$ reduction in Desulfovibrio desulfuricans G20. J Bacteriol 191: 4924-4933.

Lowe, T.M., and Eddy, S.R. (1997) tRNAscan-SE: a program for improved detection of transfer RNA genes in genomic sequence. Nucleic Acids Res 25: 955-964.

Luo, J., Cirpka, O.A., Wu, W.M., Fienen, M.N., Jardine, P.M., Mehlhorn, T.L., et al. (2005) Mass-transfer limitations for nitrate removal in a uranium-contaminated aquifer. Environ Sci Technol 39: 8453-8459.

Madden, A.S., Smith, A.C., Balkwill, D.L., Fagan, L.A., and Phelps, T.J. (2007) Microbial uranium immobilization independent of nitrate reduction. Environ Microbiol 9: 23212330.

Mander, G.J., Pierik, A.J., Huber, H., and Hedderich, R. (2004) Two distinct heterodisuilfide reductase-like enzymes in the sulfate-reducing archaeo Archaeoglobus profundus. Eur J Biochem 271: 1106-1116.

Methe, B.A., Nelson, K.E., Eisen, J.A., Paulsen, I.T., Nelson, W., Heidelberg, J.F., et al. (2003) Genome of Geobacter sulfurreducens: metal reduction in subsurface environments. Science 302: 1967-1969.

Meyer, J. (2007) [FeFe] hydrogenases and their evolution: a genomic perspective. Cell Mol Life Sci 64: 1063-1084.

Moser, D.P., Onstott, T.C., Fredrickson, J.K., Brockman, F.J., Balkwill, D.L., Drake, G.R., et al. (2003) Temporal shifts in the geochemistry and microbial community structure of an ultradeep mine borehole following isolation. Geomicrobiol $J$ 20: 517-548.

Moser, D.P., Gihring, T.M., Brockman, F.J., Fredrickson, J.K., Balkwill, D.L., Dollhopf, M.E., et al. (2005) Desulfotomaculum and Methanobacterium spp. dominate a 4-to 5-kilometer-deep fault. Appl Environ Microbiol 71: 87738783.

N'Guessan, A.L., Vrionis, H.A., Resch, C.T., Long, P.E., and Lovley, D.R. (2008) Sustained removal of uranium from contaminated groundwater following stimulation of dissimilatory metal reduction. Environ Sci Technol 42: 2999-3004.

Nevin, K.P., and Lovley, D.R. (2002) Mechanisms for Fe(III) oxide reduction in sedimentary environments. Geomicrobiol J 19: 141-159.

Newman, D.K., and Kolter, R. (2000) A role for excreted quinones in extracellular electron transfer. Nature 405: 94-97.

Nonaka, H., Keresztes, G., Shinoda, Y., Ikenaga, Y., Abe, M., Naito, K., et al. (2006) Complete genome sequence of the dehalorespiring bacterium Desulfitobacterium hafniense Y51 and comparison with Dehalococcoides ethenogenes 195. J Bacteriol 188: 2262-2274.

Odom, J.M., and Peck, H.D. (1981) Hydrogen cycling as a general mechanism for energy coupling in the sulfatereducing bacteria Desulfovibrio sp. FEMS Microbiol Lett 12: $47-50$.

Oliveira, T.F., Vonrhein, C., Matias, P.M., Venceslau, S.S., Pereira, I.A.C., and Archer, M. (2008) The crystal structure of desulfovibrio vulgaris dissimilatory sulfite reductase bound to dsrc provides novel insights into the mechanism of sulfate respiration. J Biol Chem 283: 34141-34149.

Park, H.S., Lin, S., and Voordouw, G. (2008) Ferric iron reduction by Desulfovibrio vulgaris Hildenborough wild type and energy metabolism mutants. Anton Leeuw Int $J$ G 93: $79-85$

Payne, R.B., Gentry, D.M., Rapp-Giles, B.J., Casalot, L., and Wall, J.D. (2002) Uranium reduction by Desulfovibrio desulfuricans Strain G20 and a cytochrome c3 mutant. Appl Environ Microbiol 68: 3129-3132.

Pereira, P.M., He, Q., Valente, F.M.A., Xavier, A.V., Zhou, J.Z., Pereira, I.A.C., and Louro, R.O. (2008) Energy metabolism in Desulfovibrio vulgaris Hildenborough: insights from transcriptome analysis. Anton Leeuw Int J G 93: 347-362.

Pierce, E., Xie, G., Barabote, R.D., Saunders, E., Han, C.S., Detter, J.C., et al. (2008) The complete genome sequence of Moorella thermoacetica (f. Clostridium thermoaceticum). Environ Microbiol 10: 2550-2573.

Pires, R.H., Lourenco, A.I., Morais, F., Teixeira, M., Xavier, A.V., Saraiva, L.M., and Pereira, I.A.C. (2003) A novel membrane-bound respiratory complex from Desulfovibrio desulfuricans ATCC 27774. BBA-Bioenergetics 1605: 67-82.

Pires, R.H., Venceslau, S.S., Morais, F., Teixeira, M., Xavier, A.V., and Pereira, I.A.C. (2006) Characterization of the Desulfovibrio desulfuricans ATCC 27774 DsrMKJOP complex - A membrane-bound redox complex involved in the sulfate respiratory pathway. Biochemistry 45: 249-262.

Ramamoorthy, S., Sass, H., Langner, H., Schumann, P., Kroppenstedt, R.M., Spring, S., et al. (2006) Desulfosporosinus lacus sp nov., a sulfate-reducing bacterium isolated from pristine freshwater lake sediments. Int J Syst Evol Microbiol 56: 2729-2736.

Reguera, G., McCarthy, K.D., Mehta, T., Nicoll, J.S., Tuominen, M.T., and Lovley, D.R. (2005) Extracellular electron trasnfer via microbial nanowires. Nature 435: 1098-1101.

Sass, H., Overmann, J., Rutters, H., Babenzien, H.D., and Cypionka, H. (2004) Desulfosporomusa polytropa gen. nov., sp nov., a novel sulfate-reducing bacterium from sediments of an oligotrophic lake. Arch Microbio/ 182: 204211.

Schubel, U., Kraut, M., Morsdorf, G., and Meyer, O. (1995) Molecular characterization of the gene cluster coxms/ encoding the molybdenum containing carbon monoxide dehydrogenase in Oligotropha carboxidovorans. J Bacteriol 177: 2197-2203.

Setzke, E., Hedderich, R., Heiden, S., and Thauer, R.K. (1994) H2: heterodisulfide oxidoreductase complex from Methanobacterium thermoautotrophicum: composition and properties. Eur J Biochem 220: 139-148.

Shelobolina, E.S., Coppi, M.V., Korenevsky, A.A., DiDonato, L.N., Sullivan, S.A., Konishi, H., et al. (2007) Importance of c-type cytochromes for $\mathrm{U}(\mathrm{VI})$ reduction by Geobacter sulfurreducens. BMC Microbiol 7: 16. 
Stojanowic, A., Mander, G.J., Duin, E.C., and Hedderich, R. (2003) Physiological role of the F420-non reducing hydrogenase (Mvh) from Methanothermobacter marburgensis. Arch Microbiol 180: 194-203.

Strittmatter, A.W., Liesegang, H., Rabus, R., Decker, I., Amann, J., Andres, S., et al. (2009) Genome sequence of Desulfobacterium autotrophicum HRM2, a marine sulfate reducer oxidizing organic carbon completely to carbon dioxide. Environ Microbiol 11: 1038-1055.

Tebo, B.M., and Obraztsova, A.Y. (1998) Sulfate-reducing bacterium grows with $\mathrm{Cr}(\mathrm{VI}), \mathrm{U}(\mathrm{VI}), \mathrm{Mn}(\mathrm{IV})$, and $\mathrm{Fe}(\mathrm{III})$ as electron acceptors. FEMS Microbiol Lett 162: 193-198.

Verhagen, M.F., O'Rourke, T., and Adams, M.W. (1999) The hyperthermophilic bacterium, Thermotoga maritima, contains an unusually complex iron-hydrogenase: amino acid sequence analyses versus biochemical characterization. BBA-Bioenergetics 1412: 212-229.

Vignais, P.M., and Colbeau, A. (2004) Molecular biology of microbial hydrogenases. Curr Issues Mol Biol 6: 159188.

Vignais, P.M., Billoud, B., and Meyer, J. (2001) Classification and phylogeny of hydrogenases. FEMS Microbiol Rev 25: 455-501.

Voordouw, G. (2002) Carbon monoxide cycling by Desulfovibrio vulgaris Hildenborough. J Bacteriol 184: 59035911.

Weber, K.A., Achenbach, L.A., and Coates, J.D. (2006) Microorganisms pumping iron: anaerobic microbial iron oxidation and reduction. Nat Rev Microbiol 4: 752-764.
White, D. (2000) The Physiology and Biochemistry of Prokaryotes. New York, NY, USA: Oxford University Press. Widdel, F., and Bak, F. (1992) Gram-negative mesophilic sulfate-reducing bacteria. In The Prokaryotes. Ballows, A., Truper, H.G., Dworkin, M., Harder, W., and Shleifer, K.-H. (eds). Berlin, Germany: Springer, pp. 3352-3378.

\section{Supporting information}

Additional supporting information may be found in the online version of this article.

Fig. S1. Genes involved in glycolysis in $D$. reducens. Fig. S2 Genes involved in the reductive pentose phosphate pathway in $D$. reducens.

Fig. S3 Genes involved in the partial reductive TCA cycle in D. reducens.

Fig. S4 Growth of $D$. reducens in the presence and absence of yeast extract.

Fig. S5 Genes involved in pyruvate metabolism in $D$. reducens.

Fig. S6 Inhibition of sulfate reduction in $D$. reducens by CO. Fig. S7 Fe(III) reduction by $D$. reducens.

Table S1. Genes with homology to the delta subunit of methyl-viologen hydrogenase.

Please note: Wiley-Blackwell are not responsible for the content or functionality of any supporting materials supplied by the authors. Any queries (other than missing material) should be directed to the corresponding author for the article. 